\title{
Molecular Detection of Virulent Salmonella Strains in Commercially Sold Meat in Jos Metropolis, North-Central Nigeria.
}

\author{
Anejo-Okopi AJ ${ }^{1,2}$, Adeniyi DS ${ }^{2}$, Audu O $^{3}$, Okojokwu OJ $\mathbf{J}^{1}$, Zumbes $\mathbf{J H}^{1}$, Okechalu $\mathbf{J}^{\mathbf{1}}$, \\ Augustine BB ${ }^{1}$, Ali $\mathbf{M}^{1}$, Akindigh $\mathrm{TM}^{2}$, Lar MP \\ ${ }^{1 .}$ Department of Microbiology, University of Jos, Nigeria. \\ 2. AIDS Prevention Initiative in Nigeria (Infectious Diseases Unit), \\ Jos University Teaching Hospital, Jos, Nigeria. \\ ${ }^{3 .}$ Department of Epidemiology and Community Health, College of Health Sciences, \\ Benue State University, Makurdi, Nigeria.
}

\begin{abstract}
Meat and different meat products are known to harbour myriads of pathogenic microbial organisms; and the deleterious effects of this microbial contamination is now a major cause for public health concern globally. 120 different meat products were randomly selected from thirteen different locations in the Jos Metropolis of North-Central Nigeria for this study. Microbiological culture and repeated sub-cultures yields 20/120 (16.7\%) pure Salmonella isolates; with 17/20 (85\%) of the pure Salmonella isolates testing positive for the Salmonella invA virulence gene after PCR amplification, and these were also biochemically confirmed to be pathogenic. 35/120 (29.2\%) pure isolates of Escherichia coli was also obtained after repeated culture in EMB. The PCR product which was visualized in $1.5 \% \mathrm{w} / \mathrm{v}$ agarose gel stained with ethidium bromide is a DNA fragment of 280bp. This study shows that there is a high prevalence of pathogenic and virulent Salmonella species in the study area. This may not be unassociated with the poor hygiene practices among meat handlers in the study area. It is thus concluded that the traditional microbiological methods of culture and biochemical testing are very effective in detecting pathogenic Salmonella strains. However, the use of molecular methods of detection remains the most sensitive and the most specific in the detection of both pathogenic and virulent Salmonella strains.
\end{abstract}

Keywords: Salmonella species, Escherichia coli, Virulence, invA gene, Jos

\section{INTRODUCTION}

Salmonella is one of the most important sources of food poisoning globally; with many cases of Salmonellosis reported annually [1-4]. These group of facultative Gram-negative anaerobes causes varied forms of diseases, depending on the host factors and the Salmonella serotype [5]. Salmonella has a wide range of hosts; being commonly found in the environment. Yet, some serotypes are host specific [4-5]. Salmonellosis as a common infection of food-borne origin is on the rise, and this may not be unassociated with the increase exposure of humans to animals harbouring this pathogen [6]. It is also of note that the increase prevalence, virulence, and the development of antimicrobial resistance in this pathogenic species is becoming a cause for global public health concern [5, 7].

Infection with Salmonella occurs through the ingestion of contaminated food or water; and also via the feco-oral route from infected persons. Beef, pork, poultry, and sea foods can all be contaminated with Salmonella species; and when these are incorrectly prepared can ultimately lead to Salmonellosis [8-9]. Studies have shown Salmonella contamination of animal products ranging from poultry to dairies products [9-11]. Many studies have also indicated the contamination of commonly eaten fruits and vegetables by the Salmonella species [12-18]. Also, studies have shown the isolation of Salmonella species from poultry droppings [19-20]. The isolation of Salmonella species in beef and many other meat products have also been demonstrated in some studies in Nigeria [21-22].

Salmonellosis affects all age groups but symptoms are mostly severe in children, the geriatrics, and in the immune-compromised individuals [4]. It is also of note that the Trans -placental transmission of this pathogen can also occur in very rare instances [23]. Non-typhoidal gastroenteritis, hence, salmonellosis, causes diarrhoea, vomiting, abdominal cramp, and severe electrolyte loss; which may lead to hospitalization and sometimes death [7]. 
The Nigerian population consumes a lot of meat and other different meat products; ranging from cooked beef, pork, cooked or roasted dog meat, suya (roasted beef), balangu (barbequed meat), kilishi (spiced sun-dried meat), etc. many of these meat types and meat products are well prepared at temperatures beyond the survival of many bacterial pathogens, however, due to the poor hygiene practice on the part of many meat handlers, these common place ready-to-eat meat delicacies can become contaminated with different bacterial species including Salmonella serovars. This happens when these handlers are themselves infected, are carriers, or have handled Salmonella contaminated materials or objects without proper hand washing. When these meat products are also incorrectly prepared or poorly stored, or openly displayed for sales without care, this can lead to bacterial contamination which may subsequently results into human infection upon ingestion of such contaminated food materials. Thus the practice of good hygiene is key to safeguarding the health of any population.

The cultural traditional growth and isolation of bacterial pathogens and the subsequent biochemical identification of pathogenic bacterial strains is of vital importance in the treatment and management of infectious bacterial agents; especially in low and middle income settings. However, the use of molecular methods of diagnosis provides the most reliable and the most sensitive means of identifying the virulence and pathogenic nature of different bacterial species; especially the Salmonella strains.

\section{Material AND Methods}

This study was carried out in the Jos metropolis of North-Central Nigeria. Three different local government areas, namely Jos North, Jos South, and Jos East make up the Jos metropolis. Animal husbandry is largely practiced at this part of the country; and a large proportion of the population is in the habit of regularly consuming meat and different meat products. Beef is mostly considered as a staple in most Nigerian dishes; and different other meat types such as pork and dog meat are also frequently consumed. Thirteen major spots or areas where these various meat types and their various by-products are always readily available in the Jos metropolis were visited for sampling. These areas includes Faringada market, Katako market, Chobe market, Kwararafa, Gada biu, Terminus market, Gangare market, Tafawa Balewa street, Tudun wada, Abbatoir market, Gyel market, Kugiya market, and Anguldi, respectively. The selected meat types for the study were Beef, Kilishi, Balangu, Suya, Pork, and Dog meat respectively. All samples were aseptically collected into sterile universal containers before transportation to the Laboratory for culture. 120 samples of these various meat types were randomly selected from the visited sites and used for this study.

\section{Culture of Pure Salmonella Isolates}

Several media which include Salmonella-Shigella agar (SSA), buffered peptone water, RappaportVassiliadis agar, Xylose-Lysine Deoxycholate (DCA) agar, Brain-Heart infusion broth, and Eosin Methylene Blue (EMB) among others were all used for the culture and sub-culture of the bacterial growth in this study until pure isolates of Salmonella species were obtained. Methods described by Ochei et al [24] were used for the preparation of these media. All media were autoclaved at 121 degrees centigrade for 15 minutes; except for SSA which does not require autoclaving but boiling for 15 minutes before pouring to set in a petri dish. One gram of each sample was pre-enriched in $9 \mathrm{mls}$ of buffered peptone water and incubated at 37 degree centigrade for 16 hours. After the preenrichment in peptone water, $1 \mathrm{ml}$ of the inoculum was transferred into Rappaport-Vassiliadis broth and incubated at 42 degree centigrade for 18 hours. The broth culture was then spread on DCA to get pure colonies. The pure colonies were further sub-cultured in SSA and Gram stained; with Gram negative rods microscopically observed. Biochemical tests were carried out on the pure Salmonella isolates using Andrade's peptone water, Urease test, and Simmons Citrate test [24], respectively. The biochemically positive Salmonella strains were then suspended each in Brain-Heart infusion broth for DNA extraction.

\section{DNA Extraction of Pure Salmonella Isolates}

The suspended Salmonella isolates in Brain-Heart infusion broth was briefly vortexed to make for the uniform distribution of the bacterial cells in the broth. $1 \mathrm{ml}$ of the homogenized broth-bacterial solution was transferred into $1.5 \mathrm{ml}$ already labelled micro-centrifuge tubes and centrifuged at 14,000 rpm (rate per minute) for 2 minutes to pellet the cells; after which the supernatant was discarded. 500 microliter of Nuclease free water was added to the cells; this was vortexed and then centrifuged at 14,000rpm for 2 minutes and the supernatant decanted. 200 microliter of sterile Nuclease free water 
was further added; the mixture was vortexed and the content was transferred into a pre-labelled $1.5 \mathrm{ml}$ Eppendorf tube by gentle aspiration using a micropipette. 200 microliter of Proteinase $\mathrm{K}$ was pipetted into the mixture, and 200 microliter of buffer AL was added to the mixture and mixed by pulsevortexing for 15 seconds in order to ensure sufficient lysis of the cells.

The above mixture was incubated at 56 degrees centigrade for 10 minutes; after which the tube was briefly centrifuged. 200 microliter of absolute ethanol was pipetted into the mixture and pulse vortexed for 15 seconds. The mixture was again spun before carefully applying it into a mini spin column without wetting the rim. This was spun at $8000 \mathrm{rpm}$ for 1 minute. With the tube containing the filtrate discarded, the mini spin column was placed in a $2 \mathrm{ml}$ tube. The mini spin column was carefully opened, and 500 microliter buffered AW1 was added to the spin and centrifuged at 8000rpm for 1 minute. With the collection tube for the filtrate discarded, the mini spin column was placed in another new $2 \mathrm{ml}$ collection tube, and 500 microliter of AW2 was added to the spin column and centrifuged at a full speed of 14000rpm for 3 minutes. The mini spin column was then removed and placed into a $1.5 \mathrm{ml}$ micro centrifuge tube. 200 microliter of distilled water was added to the spin column and this was incubated at Room Temperature for 1 minute; and then centrifuged at $8000 \mathrm{rpm}(6000 \mathrm{~g})$ for 1 minute in order to elute the bacterial DNA. The eluted DNA was amplified in an Eppendorf Thermocycler.

\section{Salmonella Primer Sets and PCR Amplification}

Both the forward (5' - ACA GTG CTC GTT TAC GAC CTG AAT 3') and the reversed (5' - AGA CGA CTG GTA CTG ATC GAT AAT 3') Salmonella invA virulence gene primers were used for the amplification of our pure DNA extracts using QIAGEN ${ }^{\circledR}$ kit. The molecular weight marker was a 100 base pair (bp) DNA ladder; while the positive control has a base pair of 284 . The successful amplicons from our extracted DNA products have a consistent 280bp. The Master mix used for our amplification is made up of 3 microliter of $10 \mathrm{X}$ buffer, 1 microliter of mgcl2, 1 microliter of dNTPs, 1.25 microliter each of Salmonella invA forward and reversed polymerase, 0.5 microliter of Taq, 5 microliter of our extracted DNA product, and the mixture is made up to 25 microliter with sterile water.

Amplification was carried out in an Eppendorf Thermocycler using a cycling gradient with an initial incubation stage at 95 degrees centigrade for 2 minutes. This is followed by 35 cycles of denaturation at 95 degrees centigrade for 30 seconds, annealing took place at 53 degrees centigrade for 30 seconds, elongation of the primers took place at 72 degrees centigrade for 1 minute, and extension of the annealed primers at 72 degrees centigrade for a final 7 minutes.

\section{Gel Electrophoresis}

$1.5 \% \mathrm{w} / \mathrm{v}$ agarose gel was used for the separation of our amplified products. This was prepared using agarose powder and stained with 5 microliter ethidium bromide. 2 microliter of the marker with a base pair (bp) of 100 was loaded unto the tank, followed by 5 microliter each of the positive and negative controls. 5 microliter each of the amplified products was also loaded into their corresponding positions in the agarose gel. The separation takes place using a current of 80 volts; with the positive control yielding a bp of 284 as expected, and the amplified products yielding a consistent bp of 280 respectively.

\section{ReSUlts}

The popular and or general consumption of meat and various meat products in Nigeria, and the increase in the number of gastroenteritis cases, duly informed the need for this study. A total of 120 study samples were randomly collected at thirteen different locations in Jos Metropolis, North-Central Nigeria for this study. Of the 120 samples tested, 20 were positive for Salmonella species after repeated cultures; with only 17 biochemically confirmed to be pathogenic. With the Eosin Methylene Blue (EMB) media, 35/120 (29.2\%) samples tested positive for Escherichia coli; and there were also other non-lactose fermenting colonies. The percentage of Salmonella positive cultures was $16.7 \%$ (20/120), while the percentage of biochemically confirmed pathogenic strains was $14.2 \%(17 / 120)$. The 17 biochemically confirmed strains were also positive for the Salmonella invA gene used in our study; this gives a percentage of $14.2 \%$ (17/120). Of the 20 pure Salmonella isolates, 17 were positive for the Salmonella invA virulence gene which represents $85 \%$ (17/120) of the pure isolates. 
Anejo-Okopi AJ et al.

Table 1. Percentage of meat types positive for Salmonella invA virulence gene in Jos Metropolis

\begin{tabular}{|l|l|l|l|l|l|l|}
\hline Sample types & Kilishi & Balangu & Suya & Beef & Pork & Dog meat \\
\hline Number tested & 10 & 30 & 30 & 30 & 10 & 10 \\
\hline$\%$ Positive & $3(30 \%)$ & $2(6.7 \%)$ & $4(13.3 \%)$ & $5(16.7 \%)$ & $1(10 \%)$ & $2(20 \%)$ \\
\hline
\end{tabular}

Kilishi whish is a by-product of beef has the highest pathogenic Salmonella contamination of $30 \%$. This is closely followed by beef $(16.7 \%)$ and suya $(13.3 \%)$ which is also a by-product of beef. Thus beef has a combined contamination rate of $60 \%$; while balangu has $6.7 \%$, pork (10\%), and dog meat $(20 \%)$ respectively (see table 1$)$.

\section{DisCUSSION}

Salmonella is the most common form of food-borne bacterial infection worldwide [1-5]. Most Salmonella infection, especially non-typhoidal Salmonellosis are self-limiting; except at the two extremities of life and in the immune-compromised individuals who may require urgent antimicrobial treatment [4]. Fruits and vegetables are important sources of Salmonella infections [12-18]; and also poultry farms, poultry products, beef, and other animal products like dairies [9, 11, 19-22].

Bacteriological detection through culture and biochemical analysis may be time consuming, but the benefits of these systematic microbiological processes in low and middle income settings as seen in most African countries cannot be overemphasized. However, the use of molecular detection methods provides a quick, sensitive, and the most accurate means to identifying pathogenic and virulent Salmonella strains. This is of most importance in the food industries and at water treatment Centre's where food and water for general public consumption are produced and or treated respectively.

The result of this study indicates that Salmonella species constitutes an important food-borne pathogen in the study area. This may not be unconnected to the poor hygiene practice by the meat handlers at this region. Different studies have shown the high prevalence of Salmonella species contamination of different meat types and meat products ranging from 5.92\% to $22.6 \%$ [9, 25-26]. The $14.2 \%$ confirmed prevalence rate in this study is well within the range of what most studies have indicated. Beef and its many by-products seem to be the most contaminated in this study. This may not be unassociated with the fact that beef is the most commonly eaten meat type in this part of Nigeria. The high virulence rate of $85 \%$ (17/120) in this study is a cause for public health concern in the affected population. The observed contamination in this current study could be strongly associated with the manner in which these meat handlers prepares and displays their sales meat and meat products. Lack of proper hygiene practices, and the lack of proper monitoring and licensure of these finished meat products vendors by the respective health authorities have short-changed the health and wellbeing of the affected populations.

It is thus revealed in our study, that the use of cultural and biochemical methods of detecting pathogenic Salmonella species is still very effective; though time consuming. And that in low and middle income settings as seen in Africa, this can, and will still be of great value for the foreseeable future. However, the use of molecular detection methods remains the most sensitive and effective in detecting both pathogenic and virulent Salmonella strains.

\section{Conclusion}

Of the $20(16.7 \%)$ pure Salmonella isolates in this study, 17/120 (14.2\%) tested positive for the biochemical tests and for DNA PCR. This shows that there is a high rate of Salmonella contamination of meat and different meat products in the study area. Though meat is a favorite treat for most Nigerians, the poor, unhygienic, and unsafe ways of handling this popular meat delicacies and past times has become a cause for the common reports of gastroenteritis; and thus Salmonellosis. It is therefore of utmost importance that urgent steps be taken by the key responsible organs and agencies of government at addressing this issue; in a bid to curtailing and forestalling further spread of Salmonella infections through public health education and advocacy, licensure, regular and adequate monitoring, and supervision of meat vendors and meat products vendors. Also, training of meat handlers on basic hygiene practices such as regular hand washing, environmental inspections, and compulsory regular health checks for meat handlers. These basic measures will go a long way in helping to prevent infections with Salmonella species. 


\section{REFERENCES}

[1] Center for Disease Control and Prevention: General Information on Salmonella What is Salmonellosis? Updated March 2015, Available at http://www.cdc.gov/salmonella/general/index.html.

[2] National Institute of Health - NIAID: Salmonellosis. Updated September 2015. Available at http://www.niaid.nih.gov/topics/salmonellosis/pages/default.aspx.

[3] Food Safety.gov: Salmonella. First issue 2016. Availbale at http://www.foodsafety.gov /poisoning/ causes/bacteriaviruses/salmonella/.

[4] WHO Media Centre: Salmonella (non-typhoidal). Fact Sheet No. 139. Updated August 2013, Available at http://www.int/mediacentre/factsheets/fs139/en/.

[5] Michael, DO: Salmonella Infection in Emergency Medicine. Medscape Reference. Available at http://emedecine.medscape.com/article/785774-overview.

[6] Linam WM, Gerber MA: Changing Epidemiology and Prevention of Salmonella Infections. Pediatr Infect Dis J. 2007, Aug. 26(8): 747-8. [Medline].

[7] Weinberger M and Keller N: Recent trends in the epidemiology of non-typhoidal Salmonella and antimicrobial resistance - the Israeli experience and worldwide review. Curr Opin Infect Dis. 2005, Dec; 18(6): 513-21.

[8] "FDA/CFSAN: Food Safety A to Z Reference Guide - Salmonella". FDA - Center for Food Safety and Applied Nutrition. 2008-07-03. Archived from the original on January 17, 2009, Retrieved 2009-02-14.

[9] Moussa IM, Gassem MA, Al-Doss AA, Mahmoud WAS, and Abdel M: Using molecular techniques for rapid detection of Salmonella serovars in frozen chicken and chicken products collected from Riyadh, Saudi Arabia. Afr. J. Biotech, 2010; Vol. 9(5). pp. 612-619, 1st Feb, 2010. Available online at http://www.academicjournals.org/AJB.

[10] Mayada MG, and Maha AMA: Culture versus PCR for Salmonella Species Identification in some Dairy products and Dairy handlers with special concern to its Zoonotic importance. Vet. Med. Int. (2014) Vol. 2014, article ID 502370; 5 Pages. Available online at http://dx.doi.org/10.1155/2014/502370.

[11] Kumarss A, Taghi ZS, Gholamreza N, Reza R, Javid A, and Shahrnaz BA: Molecular detection on invA and spv virulence genes in Salmonella enteriditid isolated from human and animals in Iran. Afr. J. Microbiol. Res. 2010,. Vol. 4(21); pp. 2202-2210. 4th Nov, 2010, Available at http://www.academicjournals.org/ajmr.

[12] Raufa AI, Zongur L, Lawan FA, Bello HS, Adamu MS, Ameh JA, and Ambali AG: Prevalence and antimicrobial profiles of Salmonella serovars from vegetables in Maiduguri, North eastern Nigeria. S. J. Vet. Sci. 2014, Vol. 12(1): 23-28.

[13] Quiroz-Santiago C, Rodas-Suarez OR, Carlos RV, Fernandez FJ, Quinones-Ramirez EL, and Vazquez-Salinas C: Prevalence of Salmonellosis in vegetables from Mexico. J. Food Prot. 2009, June; 72(6): 1279-82.

[14] Eni AO, Oluwawemitan IA, and Solomon OU: Microbial quality of fruits and vegetables sold in Sango Ota, Nigeria. Afr. J. F. Sci. 2010;. Vol. 4(5); pp. xxx-xxx May 2010. Available at http://www.academicjournals.org/ajfs.

[15] Bagudo AI, Tambuwal FM, Faleke OO, Egwu OO, and Aliero AA: Prevalence of Salmonella serotypes in Sokoto abbatoir effluents and vegetables cultivated around the abbatoir. Microbiol. Res. Int. 2014, Vol. 2(2); pp. 13-17, April 2014.

[16] Teklemichael T, Askalu W, Baymot D, Betelihem D, and Dabuol D: Microbial Quality of Fresh Lettuce Irrigated with Untreated Waste Water Around Askum University, Central Zone of Tigrai. Europen Journal of Business and Management 2015, Vol. 7(21).

[17] Ait MA, Hassani L, and Rafouk L: Salmonella contamination of vegetables irrigated with untreated wastewater. World J. Microbio \& Biotech (2001). March 2001, Vol. 17, issue 2 pp. 207-209.

[18] Wells JM, and Butterfield JE: Salmonella contamination Associated with Bacterial Soft Rot of Fresh Fruits and Vegetables in the Marketplace. Plant Dis. 199; 81:867-872. 
[19] Okwori AEJ, Ogbe RJ, Chollom SC, Agada GOA, Ujah A, Okwori E, Adeyanju ON, and Echeonwu GON: Isolation of Salmonella gallinarum from Poultry Droppings in Jos Metropolis, Plateau State, Nigeria. IOSR Journal of Agriculture and Veterinary Science (IOSR-JAVS) 2013. 5(2): 41-44.

[20] Orji MUI, Onuigbo HC, and Mbata TI: Isolation of Salmonella from Poultry Droppings and other environmental sources in Awka, Nigeria. Int. J. Infec. Dis. 2005, 9(2): 86-89.

[21] Tafida SY, Kabir J, Kwaga JKP, Bello M, Umoh VJ, Yakubu SE, Nok AJ, and Hendriksen R: Occurence of Salmonella in retail beef and related meat products in Zaria, Nigeria. Food and Agriculture Organization of the United Nations. AGRIS, 2013.

[22] Adesiji YO, Alli OT, Adekanle MA, and Jolayemi JB: Prevalence of Arcobacter, Escherichia coli, Staphylococcus aureus and Salmonella species in Retail Raw Chiken, Pork, Beef, and Goat meat in Osogbo, Nigeria. Sierra Leone Journal of Biomedical Rresearch, 2011, Apil, Vol. 3(1); $8-12$

[23] Rai B, Utekar T, and Ray R: Preterm delivery and neonatal meningitis due to transplacental acquisition of non-typhoidal Salmonella serovar montevideo. BMJ Case Rep. 2014, May 29. 2014: [Medline].

[24] Ochei J, and Kolhutkar A: Medical Laboratory Science - Theory and Practice. Tata McGrawHill Publishing Company Limited; New Delhi. 2000, pp. 834-856.

[25] Mohammad MSD, Mohammad KSY, Nima M, and Enayat K: Prevalence of Salmonella species in packed and unpacked red meat and chicken in South of Tehran. Jundishapur J. Microbiol. 2014, Apr; 7(4): e9254. doi: 10.5812/jjm.9254

[26] Gladys TA, and Olayinka I: Salmonella and Escherichia coli contamination of poultry meat from a processing plant and retail markets in Ibadan, Oyo State, Nigeria. SpringerPlus. 2014, 3:139. doi:10.1186/2193-1801-3-139. 